\title{
Analisis Risiko Kejadian Bayi Berat Lahir Rendah (BBLR) pada Pasien Preeklamsi di Rumah Sakit Umum Pusat Dr. Hasan Sadikin Periode Januari-Desember 2019
}

\author{
Tri Karyadi, Hanom Husni Syam, Hartanto Bayuaji \\ Departmen Obstetri dan Ginekologi, Fakultas Kedokteran Universitas Padjadjaran/ \\ RSUP Dr. Hasan Sadikin, Bandung \\ Korespondensi: Tri karyadi, Email: Tri.fkunpad@gmail.com
}

\begin{abstract}
Abstrak
Tujuan: Untuk mengetahui risiko kejadian bayi berat lahir rendah (bblr) pada pasien preeklamsi di RSUP Dr. Hasan Sadikin periode Januari - Desember 2019 .

Metode: Penelitian ini menggunakan desain penelitian observasional analitik dengan pendekatan cross-sectional (potong lintang). Data dikumpulkan dari data yang tersedia pada rekam medis pasien yang melakukan persalinan di RSUP Dr. Hasan Sadikin pada bulan Januari hingga bulan Desember tahun 2019.

Hasil: Terdapat $252(11,4 \%)$ ibu hamil dengan preeklamsi dari seluruh subjek. Prevalensi BBLR pada subjek total adalah 49,2\%. Bayi dengan BBLR lebih banyak terjadi pada kelompok preeklamsi dibandingkan dengan kelompok non preeklamsi, yaitu 60,3\% dibandingkan 47,8\% ( $<<0,001)$. Kelompok preeklamsi memiliki rerata BBL yang lebih rendah secara signifikan dibandingkan kelompok non preeklamsi, yaitu 2.255,6 + 741,5 gram dibandingkan 2.465,5+696,2 gram $(\mathrm{p}<0,001)$.

Kesimpulan: Terdapat hubungan bermakna antara preeklamsi dengan kejadian BBLR di Rumah sakit Hasan Sadikin.
\end{abstract}

Kata kunci: Preeklampsi, BBLR, abnormal plasentasi

\section{Risk Analysis of the Incidence of Low Birth Weight Infants in Preeclampsia Patient in Dr. Hasan Sadikin General Hospital Period January-December 2019}

\begin{abstract}
Objective: Find risk of low body weight (LBW) babies on preeclampsia at RSUP Dr. Hasan Sadikin period January - December 2019.

Method: This study used an analytical observational research design with a cross-sectional approach. The data collected is based on the results of the data available in the medical records of patients who gave birth at Dr. RSUP. Hasan Sadikin in January to December 2019.

Result: There were $252(11.4 \%)$ pregnant women with preeclampsia from all subjects. The prevalence of $L B W$ in total subjects was $49.2 \%$. Babies with LBW were more common in the preeclampsia group compared to the nonpreeclampsia group, namely $60.3 \%$ compared to $47.8 \%(p<0.001)$. The preeclampsia group had a significantly lower mean BBL than the non-preeclampsia group, which was 2,255.6 + 741.5 grams compared to $2,465.5+$ 696.2 grams $(p<0.001)$.

Conclusion: It can be concluded that there is a significant relationship between preeclampsia and the incidence of LBW at Hasan Sadikin Hospital.
\end{abstract}

Key word: Preeclampsia, $L B W$ 


\section{Pendahuluan}

Preeklamsi didefinisikan sebagai peningkatan tekanan darah (tekanan sitolik $\geq 140 \mathrm{mmHg}$ atau diastolik $\geq 90 \mathrm{mmHg}$ ) pada wanita yang sebelumnya memiliki tekanan darah normal dan proteinuria, atau gejala klinis berat. Preeklamsi diperkirakan memengaruhi $5-7 \%$ dari semua wanita hamil. ${ }^{1}$ Insiden preeklampsia di Indonesia sendiri adalah 128.273/tahun atau sekitar 5,3\%. ${ }^{7}$ Preeklamsi berkembang melalui abnormalitas plasentasi yang diikuti dengan sindrom yang ditandai dengan faktor anti-angiogenik berlebih. Plasenta yang berimplantasi secara abnormal ini menyebabkan perfusi plasenta yang buruk dan menyebabkan keadaan hipoksia pada janin. Hipoksia pada janin menyebabkan berat badan yang rendah. ${ }^{1,8}$

BBLR (Bayi Berat Lahir Rendah) adalah berat lahir $<2.500$ gram. Bayi dengan BBLR memiliki risiko kematian $>20$ kali lebih besar dibandingkan dengan bayi dengan berat lahir $>2.500$ gram. Selain itu, BBLR diasosiasikan dengan disabilitas neurologis jangka panjang, perkembangan bahasa yang terhambat, dan peningkatan risiko penyakit-penyakit kronis. Di seluruh dunia, estimasi BBLR terjadi pada 15-20\% kehamilan tiap tahunnya. ${ }^{9}$

Penelitian yang dilakukan oleh Irwinda dkk dan Mitao dkk. menemukan bahwa preeklampsia berat memiliki pengaruh yang bermakna secara statistik terhadap BBLSR $(\mathrm{OR}=11,45 ; 95 \%$ CI-2,77-47,38) dan BBLR $(\mathrm{OR}=6,57 ; 95 \% \mathrm{CI}=4,01-10,79) \quad(\mathrm{RR} 3.9$; $95 \%$ CI $3.6-4.2){ }^{8,10}$

Hingga saat ini belum ada penelitian mengenai analisis risiko kejadian BBLR pada pasien preeklampsia yang dilakukan di RS Hasan Sadikin, Bandung. Sehingga peneliti ingin mengisi kesenjangan tersebut melalui penelitian ini.

\section{Metode}

Penelitian ini menggunakan desain penelitian observasional analitik dengan pendekatan cross-sectional (potong lintang). Data yang dikumpulkan berdasarkan hasil data yang tersedia pada rekam medis pasien yang melakukan persalinan di RSUP Dr. Hasan Sadikin, Bandung pada bulan Januari hingga bulan Desember tahun 2019.

Subjek yang diikutsertakan pada penelitian ini adalah seluruh pasien rawat inap yang melahirkan di Departemen/KSM Obstetri dan Ginekologi RSUP Dr. Hasan Sadikin, Bandung pada periode 1 Januari 31 Desember 2019. Pasien dengan penyakit jantung, anemia, kehamilan kembar, pasien dengan janin yang memiliki kelainan kongenital, dan pasien dengan data rekam medis yang tidak lengkap dieksklusi dari penelitian ini. Pasien dengan penyakit jantung, anemia, kehamilan kembar, pasien dengan janin yang memiliki kelainan kongenital dieksklusi karena memiliki risiko lebih tinggi untuk tejadinya BBLR sehingga dapat menyebabkan bias dari hasil penelitian.

Luaran yang dinilai dalam penelitian ini adalah kejadian BBLR yang didefinisikan sebagai berat lahir kurang dari 2500 gram. Selanjutnya BBLR dibagi berdasarkan derajatnya menjadi tiga kelompok, yaitu (1) BBLR jika berat lahir 1.500 - 2.499 gram, (2) berat badan lahir sangat rendah (BBLSR) jika berat 1.000 - 1.499 gram, dan (3) berat badan lahir amat sangat rendah (BBLASR) jika berat lahir $500-<1.000$ gram. Sedangkan variabel bebas dari penelitian ini adalah kejadian preeklamsi.

Penelitian ini dilakukan setelah mendapat persetujuan dan rekomendasi dari Komite Etik Penelitian Kesehatan, Fakultas Kedokteran Universitas Padjadjaran - RSUP Dr. Hasan Sadikin Bandung. Kerahasiaan data pasien dijaga dengan memastikan bawa rekam medis tidak disebarluaskan tanpa izin pasien yang bersangkutan dan data nama pasien diganti dengan kode numerik.

Data dianalisis dengan perangkat lunak SPSS versi 23 (IBM Corp., Armonk, 
New York, USA). Deskripsi data kategorik dilakukan dengan menggunakan frekuensi dan proporsi. Uji Chi-Square dilakukan untuk menganalisis hubungan antara kejadian preeklamsi dengan kejadian BBLR. Hasil dinyatakan bermakna secara statistik jika nilai $\mathrm{p}<0,05$.

\section{Hasil}

Telah dilakukan penelitian cross sectional (potong lintang) terhadap 2.214 pasien rawat inap di Departemen/KSM Obstetri dan Ginekologi RSUP Dr. Hasan Sadikin, Bandung pada periode 1 Januari - 31 Desember 2019.

Berdasarkan hasil pengumpulan data, didapatkan bahwa ibu hamil yang mengalami preeklamsi berjumlah 252 orang $(11,4 \%)$ dari seluruh subjek yang berjumlah 2.214 orang. Dari seluruh subjek, 210 orang berada pada kelompok umur kurang dari 20 tahun, 1.538 orang berada pada kelompok usia 20-35

Tabel 1 Karakteristik Subjek Penelitian tahun, dan 466 orang berada pada kelompok usia di atas 35 tahun. Berdasarkan tingkat paritas, terdapat 864 orang dalam kelompok primipara, 1.283 orang dalam kelompok multipara (1-4), dan 67 orang dalam kelompok grande multipara $(>5)$. Jenis persalinan yang banyak dilakukan adalah persalinan spontan pervaginam sebanyak $1.071 \quad(48,4 \%)$, selanjutnya seksio sesarea sebanyak 1.003 (45,3\%), ekstraksi forsep sebanyak 124 (5,6\%), ekstraksi vakum sebanyak $12(0.5 \%)$, dan lainnya sebanyak $4(0.2 \%)$. Karakteristik subjek meliputi umur, tingkat paritas, metode persalinan, dan tekanan darah disajikan pada Tabel 1.

Berdasarkan tabel 1, didapatkan bahwa tidak didapatkan perbedaan bermakna pada variabel umur antara kelompok preeklamsi dan non preeklamsi (p 0,678). Sedangkan pada variabel paritas, metode persalinan, dan tekanan darah, didapatkan bahwa terdapat perbedaan bermakna antara kelompok preeklamsi dan non preeklamsi $(\mathrm{p}<0,001)$.

\begin{tabular}{|c|c|c|c|}
\hline \multirow[b]{2}{*}{ Variabel } & \multicolumn{2}{|c|}{ Kelompok } & \multirow[b]{2}{*}{$\mathbf{p}$} \\
\hline & $\begin{array}{l}\text { Preeklamsi } \\
252(11,4 \%)\end{array}$ & $\begin{array}{c}\text { Non Preeklamsi } \\
1.962(\mathrm{n}=\mathbf{8 8 . 6 \%})\end{array}$ & \\
\hline Umur (tahun) & & & 0,678 \\
\hline Rerata & $28,6 \pm 7,4$ & $28,8 \pm 6,9$ & \\
\hline Rentang & $14-47$ & $14-46$ & \\
\hline \multicolumn{4}{|l|}{ Paritas n $(\%)$} \\
\hline 0 & $130(51,6)$ & $734(37,4)$ & \\
\hline $1-4$ & $114(45,2)$ & $1.169(59,6)$ & $<0,001$ \\
\hline$>4$ & $8(3,2)$ & $59(3,0)$ & \\
\hline \multicolumn{4}{|l|}{ Metode persalinan n (\%) } \\
\hline Spontan pervaginam & $23(9,1)$ & $1.048(53,4)$ & \\
\hline Seksio sesarea & $184(73,0)$ & $819(41,7)$ & $<0,001$ \\
\hline Ekstraksi forsep & $44(17,5 \%)$ & $80(4,1)$ & \\
\hline Ekstraksi vakum & $1(0,4)$ & $11(0,6)$ & \\
\hline Lainnya & $0(0,0)$ & $4(0,2)$ & \\
\hline \multicolumn{4}{|c|}{ Tekanan darah $(\mathrm{mmHg}) \pm \mathrm{SD}$} \\
\hline Sistolik & $163,4 \pm 9,3$ & $123,0 \pm 13,2$ & $<0,001$ \\
\hline Diastolik & $105,2 \pm 7,8$ & $80,0 \pm 8,52$ & \\
\hline
\end{tabular}


Tabel 2 Hubungan antara Preeklamsi dengan BBL

\begin{tabular}{|c|c|c|c|}
\hline \multirow{2}{*}{ BBL (gram) } & \multicolumn{2}{|c|}{ Kelompok } & \multirow[b]{2}{*}{$\mathbf{p}$} \\
\hline & Preeklamsi & Non Preeklamsi & \\
\hline Rerata \pm SD & $2.255,6 \pm 741,5$ & $2.465,5 \pm 696,2$ & $<0,001$ \\
\hline \multicolumn{4}{|l|}{ Klasifikasi n (\%) } \\
\hline$<1.000$ & $10(4,0)$ & $46(2,3)$ & \\
\hline $1.000-1.499$ & $33(13,1)$ & $129(6,6)$ & $<0,001$ \\
\hline $1.500-2.499$ & $109(43,3)$ & $762(38,8)$ & \\
\hline$>2.500$ & $100(39,7)$ & $1.025(52,2)$ & \\
\hline
\end{tabular}

Kelompok preeklamsi memiliki $<1.000$ gram $(4,0 \%)$.

karakteristik subjek yang didominasi oleh kelompok usia 20-35 tahun $(67,5 \%)$, primipara $(51,6 \%)$, metode persalinan dengan seksio sesarea $(73,0 \%)$, dan rerata tekanan darah sistolik dan diastolik yang lebih tinggi dibandingkan kelompok non preeklamsi, yaitu rerata tekanan sistolik $163,4+9,3$ dan diastolik 105,2 + 7,8 mmHg. Sedangkan pada kelompok non preeklamsi, subjek didominasi oleh kelompok usia 20-35 tahun $(69,7 \%)$, multipara $(59,6 \%)$, metode persalinan spontan pervaginam $(53,4 \%)$, dan rerata tekanan sistolik $123,0+13,2$ dan diastolik 80,0 + 8,52 $\mathrm{mmHg}$.

Berdasarkan Tabel 2, analisis bivariat menunjukkan bahwa terdapat hubungan berrmakna antara preeklamsi dengan berat badan lahir (BBL). Bayi dengan BBLR lebih banyak terjadi pada kelompok preeklamsi dibandingkan dengan kelompok non preeklamsi, yaitu $60,3 \%$ dibandingkan 47,8\% ( $\mathrm{p}<0,001)$. Kelompok preeklamsi memiliki rerata BBL yang lebih rendah secara signifikan dibandingkan kelompok non preeklamsi, yaitu $2.255,6+741,5$ gram dibandingkan 2.465,5 $+696,2$ gram (p $<0,001$ ). Jika BBL dikelompokkan menjadi $<1.000$ gram, 1000-1.499 gram, 1.5002.499 gram, dan $>2.500$ gram, tetap terdapat perbedaan signifikan antara kelompok preeklamsi dan non preeklamsi ( $\mathrm{p}<0,001)$. Kelompok ibu dengan preeklamsi paling banyak melahirkan bayi dengan BBL 1.5002.499 gram $(43,3 \%)$ diikuti oleh $>2.500$ gram $(39,7 \%)$, 1000-1.499 gram $(13,1 \%)$, dan

\section{Pembahasan}

Pada penelitian ini, didapatkan angka terjadinya preeklamsi adalah $11,4 \%$ dari seluruh subjek yang berjumlah 2.214 orang. Angka ini jauh lebih tinggi dari insidensi preeklamsi di Indonesia yang berkisar di angka 128.27/tahun atau sekitar 5,3\%.7 Studi lain juga menunjukkan prevalensi preeklamsi yang lebih rendah, yaitu $4,9 \%$ pada studi yang dilakukan oleh Samani et al. ${ }^{11}$ dan 1,3\% pada studi yang dilakukan oleh Khader et al. ${ }^{12}$ Samani et al. melakukan studi pada 5.166 persalinan dari 103 rumah sakit di Tehran, Iran pada tahun $2015^{11}$, sedangkan Khader et al. melakukan studi pada total 21.928 subjek dari 18 rumah sakit di Jordan pada periode Maret 2011 hingga April 2012.. ${ }^{2}$

Faktor usia tidak memiliki perbedaan bermakna antara kelompok preeklamsi dan non preeklamsi pada penelitian ini. Pada penelitian ini, kelompok preeklamsi memiliki karakteristik subjek yang didominasi oleh kelompok usia 20-35 tahun (67,5\%). Hasil ini berbeda dengan studi yang dilakukan oleh Samani et al. yang menunjukkan bahwa terdapat perbedaan signifikan pada umur antara kelompok preeklamsi dan non preeklamsi, yaitu 30,26 + 5,68 tahun dibandingkan 29,17 +5,44 tahun (p 0,002). ${ }^{11}$ Berdasarkan studi yang dilakukan oleh Aabidha et al. pada 1.900 subjek di Tamil Nadu pada Agustus 2010 hingga Juli 2011, didapatkan distribusi kelompok umur paling 
banyak pada preeklamsi adalah kelompok umur 21-25 tahun sebanyak 46,23\%. ${ }^{13}$ Sedangkan studi yang dilakukan oleh Khader et al. menunjukkan bahwa preeklamsi paling banyak terjadi pada kelompok usia $>40$ tahun. ${ }^{12}$

Kelompok preeklamsi pada penelitian ini didominasi oleh kelompok primipara $(51,6 \%)$. Hasil ini sesuai dengan penelitian lain, seperti penelitian yang dilakukan oleh Aabidha et al. yang menunjukkan bahwa kelompok preeklamsi terutama terdiri dari kelompok primigravida $(61,2 \%) .{ }^{13}$ Khader et al. juga menunjukkan bahwa insidensi tertinggi preeklamsi berada pada kelompok primipara. $^{12}$

Metode persalinan yang paling banyak dilakukan pada kelompok preeklamsi berdasarkan penelitian ini adalah seksio sesarea $(73,0 \%)$. Samani et al. juga menunjukkan bahwa prevalensi seksio sesarea pada kelompok preeklamsi secara signifikan lebih tinggi dibandingkan kelompok non preeklamsi, yaitu $80,65 \%$ dibandingkan 70,49\% (OR 1,92; 95\% CI 1,24-2,98; p 0,003). ${ }^{11}$ Hasil studi dari Khader et al. juga menunjukkan bahwa seksio sesarea secara signifikan lebih tinggi pada kelompok preeklamsi dibandingkan dengan kelompok non preeklamsi, yaitu 59,4\% dibandingkan $28,6 \%{ }^{12}$ Analisis bivariat pada penelitian ini menunjukkan bahwa terdapat hubungan berrmakna antara preeklamsi dengan BBL. Bayi dengan BBLR lebih banyak terjadi pada kelompok preeklamsi dibandingkan dengan kelompok non preeklamsi, yaitu $60,3 \%$ dibandingkan $47,8 \%(\mathrm{p}<0,001)$. Hal ini sesuai dengan studi yang dilakukan oleh Tshotetsi et al. berupa studi kasus kontrol pada 1.073 subjek dari empat rumah sakit di Tshwane, Afrika Selatan pada tahun 2014. Tshotetsi et al. menyebutkan bahwa preeklamsi menjadi faktor risiko terjadinya BBLR dengan nilai OR 3,74 (95\% CI 1,048,84). ${ }^{14}$

Hasil yang sama juga ditunjukkan oleh studi potong lintang yang dilakukan oleh Ekubagewargies et al. dari bulan April 2017 hingga Mei 2018 di Ethiopia. Total subjek pada studi tersebut berjumlah 240 orang dengan rerata usia $27,1+5,3$ tahun dan $43,5 \%$ subjek merupakan primipara. Prevalensi BBLR pada studi tersebut 12,9\%. Ekubagewargies et al. menunjukkan adanya hubungan antara preeklamsi dengan kejadian BBLR. Berdasarkan analisis bivariat, risiko melahirkan bayi dengan BBLR berkurang 81\% pada subjek tanpa preeklamsi (OR 0,193; 95\% CI 0,0516-0,723). ${ }^{15}$ Angka terjadinya BBLR juga lebih tinggi pada kelompok preeklamsi dibandingkan kelompok non preeklamsi pada studi yang dilakukan oleh Khader et al., yaitu 32,5\% dibandingkan $8,3 \% .^{12}$ Aabidha et al. juga menunjukkan bawa salah satu komplikasi luaran neonatal yang paling banyak terjadi pada preeklamsi adalah BBLR (7,52\%). ${ }^{13}$

Hasil ini berbeda dengan studi yang dilakukan oleh Samani et al. Pada studi Samani et al, terdapat $4,93 \%$ kasus BBL pada kelompok preeklamsi. Angka ini lebih rendah dibandingkan pada kelompok non preeklamsi, yaitu 15,32\%. Namun, tidak ditemukan adanya hubungan signifikan antara preeklamsi dengan BBL (OR 1,19; 95\% CI 0,61-2,31; $p$ 0,599). ${ }^{11}$

Pada penelitian ini, persalinan prematur memiliki hubungan yang signifikan dengan terjadinya BBLR. Hasil ini sesuai studi Tshotetsi et al. yang menyebutkan bahwa persalinan prematur juga menjadi faktor risiko terjadinya BBLR dengan nilai OR 7,15 (95\% CI 5,18-9,89). ${ }^{14}$ Ekubagewargies et al. juga menunjukkan bahwa subjek yang melahirkan secara prematur memiliki risiko 17,6 kali lipat lebih tinggi untuk melahirkan bayi dengan BBLR (OR 17,6; 95\% CI 5,18$60,17) .{ }^{15}$

Terdapat perbedaan signifikan pada skor APGAR 1 menit antara kelompok preeklamsi dan non preeklamsi pada studi ini. Studi yang sesuai dengan hasil penelitian 
ini adalah Aadibha et al. yang menyebutkan bahwa sekitar $10 \%$ bayi lahir memiliki skor APGAR kurang dari $5 .{ }^{13}$ Khader et al. juga menunjukkan bahwa bayi yang lahir dari kelompok preeklamsi lebih berisiko memiliki skor APGAR 1 menit dan 5 menit yang lebih rendah. ${ }^{12}$ Studi lainnya yang menyebutkan hal serupa adalah Ayaz et al. yang menunjukkan bahwa preeklamsi menyebabkan penurunan dari skor APGAR. ${ }^{16}$

Tidak ditemukan adanya hubungan antara preeklamsi dengan kejadian prematur pada penelitian ini. Hasil ini berbeda dengan Samani et al. yang menunjukkan adanya perbedaan signifikan pada kejadian prematur antara kelompok preeklamsi dan non preeklamsi, yaitu $8,94 \%$ dibandingkan $20,16 \%$ dengan nilai OR 2,57 (p 0,001). Setelah menyesuaikan variabel perancu berupa usia ibu, pendidikan ibu, pekerjaan ibu, BMI sebelum hamil, tingkat paritas, peningkatan berat badan saat kehamilan, dan jumlah abortus spontan dengan regresi logistik, tetap terdapat hubungan signifikan antara preeklamsi dan kejadian prematur (OR 4,19; 95\% CI 2,71-6,48; p 0,001). ${ }^{11}$

Kelemahan penelitian ini adalah penelitian yang dilakukan di rumah sakit rujukan tersier sehingga hasil penelitian dapat berbeda jika diaplikasikan pada kondisi umum. Selain itu, belum dilakukan analisis multivariat terhadap variabel perancu seperti usia ibu, tingkat paritas, ras, status sosioekonomi, tingkat pendidikan, dan komorbid sehingga dapat mengendalikan pengaruh dari variabel perancu tersebut terhadap hasil analisis. Diperlukan penelitian lebih lanjut dengan metode penelitian kasuskontrol atau kohort untuk dapat menentukan arah hubungan serta mekanisme yang mendasari hubungan antara preeklamsi dengan BBLR. Simpulan kejadian preeklamsi terjadi pada $11,4 \%$ dari seluruh subjek yang berjumlah 2.214 orang. Kelompok preeklamsi memiliki karakteristik subjek yang didominasi oleh kelompok primipara
$(51,6 \%)$, metode persalinan dengan seksio sesarea $(73,0 \%)$, dan rerata tekanan sistolik $163,4+9,3$ dan diastolik 105,2 + 7,8 mmHg. Analisis bivariat menunjukkan adanya hubungan bermakna antara preeklamsi dengan kejadian BBLR. Prevalensi BBLR pada subjek total adalah $49,2 \%$, dengan $60,3 \%$ berada pada kelompok preeklamsi dan $47,8 \%$ pada kelompok non preeklamsi. Selain BBLR, terdapat juga perbedaan bermakna pada variabel skor APGAR 1 menit antara kelompok preeklamsi dan non preeklamsi.

\section{Daftar Pustaka}

1. Rana S, Lemoine E, Granger JP, Karumanchi SA. Preeclampsia: pathophysiology, challenges, and perspectives. Circulation research. 2019;124(7):1094-112.

2. Cunningham $\mathrm{F}$, Leveno $\mathrm{K}$, Bloom $\mathrm{S}$, Spong CY, Dashe J. Williams obstetrics, 24e: Mcgraw-hill; 2014.

3. Dagnachew T, Yigeremu M. Survival of Preterm Neonates and its Determinants in Teaching Hospitals of Addis Ababa University. J Women's Health Care. 2019;8(461):2167-0420.1000461.

4. Espinoza J, Vidaeff A, Pettker CM, Simhan H. Gestational hypertension and preeclampsia. Obstetrics and Gynecology. 2019;133(1):E1-E25.

5. Kementerian Kesehatan Republik Indonesia. Profil Kesehatan Indonesia Tahun 2017. 2018.

6. Sungkar A, Fattah AN, Surya R, Santoso BI, Zalud I. High preterm birth at Cipto Mangunkusumo Hospital as a national referral hospital in Indonesia. Medical Journal of Indonesia. 2017;26(3):198203.

7. Perkumpulan Obstetri dan Ginekologi Indonesia. Panduan Nasional Pelayanan Kedokteran (PNPK) tentang Preeklampsia.[internet]. Jakarta: Perkumpulan Obstetri dan Ginekologi 
Indonesia. 2015.

8. Mitao M, Philemon R, Obure J, Mmbaga BT, Msuya S, Mahande MJ. Risk factors and adverse perinatal outcome associated with low birth weight in Northern Tanzania: a registry-based retrospective cohort study. Asian pacific journal of Reproduction. 2016;5(1):75-9.

9. Cutland CL, Lackritz EM, MallettMoore T, Bardají A, Chandrasekaran $\mathrm{R}$, Lahariya $\mathrm{C}$, et al. Low birth weight: Case definition \& guidelines for data collection, analysis, and presentation of maternal immunization safety data. Vaccine. 2017;35(48Part A):6492.

10. Irwinda R, Surya R, Nembo LF. Impact of pregnancy-induced hypertension on fetal growth. Medical Journal of Indonesia. 2016;25(2):104-11.

11. Omani-Samani R, Ranjbaran M, Amini $\mathrm{P}$, Esmailzadeh A, Sepidarkish $\mathrm{M}$, Almasi-Hashiani A. Adverse maternal and neonatal outcomes in women with preeclampsia in Iran. The Journal of Maternal-Fetal \& Neonatal Medicine. 2019;32(2):212-6.

12. Khader YS, Batieha A, Al-njadat RA, Hijazi SaS. Preeclampsia in Jordan: incidence, risk factors, and its associated maternal and neonatal outcomes. The journal of maternal-fetal \& neonatal medicine. 2018;31(6):770-6.

13. Aabidha PM, Cherian AG, Paul E, Helan J. Maternal and fetal outcome in preeclampsia in a secondary care hospital in South India. Journal of family medicine and primary care. 2015;4(2):257.

14. Tshotetsi L, Dzikiti L, Hajison P, Feresu S. Maternal factors contributing to low birth weight deliveries in Tshwane District, South Africa. PloS one. 2019;14(3).

15. Ekubagewargies DT, Kassie DG, Takele WW. Maternal HIV infection and preeclampsia increased risk of low birth weight among newborns delivered at University of Gondar specialized referral hospital, Northwest Ethiopia, 2017. Italian journal of pediatrics. 2019;45(1):7. 16. AyazA, Muhammad T, Hussain SA, Habib S. Neonatal outcome in pre-eclamptic patients. Journal of Ayub Medical College Abbottabad. 2009;21(2):53-5 